\title{
SOBRE SI EL VICEPRESIDENTE DE LA REPÚBLICA ELECTO ES TITULAR DE UN CARGO DE LEGISLADOR.
}

\author{
SOBRE SE O VICE-PRESIDENTE DA REPÚBLICA ELEITO É TITULAR \\ DE POSIÇÃO DE PARLAMENTAR.
}

\begin{abstract}
ON WHETHER THE VICE PRESIDENT OF THE REPUBLIC IS THE HOLDER OF A SENATOR POSITION.
\end{abstract}

Dr. Luis Fleitas de León*

RESUMEN. El propósito de este trabajo es estudiar de modo integral y sistémico el cargo de Vicepresidente de la República, su naturaleza, su estatuto y todos sus aspectos, tomando como eje central el debate sobre si el suyo es un cargo de legislador en tanto Senador.

PALABRAS CLAVE. Vice Presidente. Legislador. Senador. Naturaleza. Estatuto.

ABSTRACT. The aim of this paper is to study the position of Vice President of the Republic, comprehensively and systemically, in consideration of its nature, regulations and all its aspects, taking as a central axis the debate on whether or not $\mathrm{s} / \mathrm{he}$ is the holder of a Senator position.

KEYWORDS. Vice President. Legislator. Senator. Nature. Regulations.

RESUMO. O objetivo desse trabalho é estudar de forma abrangente e sistémica o cargo de Vice-Presidente da República, levando em consideração sua natureza, o seu estatuto e todos os seus aspectos, tendo como eixo central o debate sobre se ele/a é ou não titular de um cargo de parlamentar em tanto senador.

PALAVRAS CHAVE. Vice-presidente. Legislador. Senador. Natureza. Estatuto.

" Profesor Adjunto (Grado 3 contratado) de Derecho Constitucional, Universidad de la República. Doctor en Derecho y Ciencias Sociales. Máster en Derecho Constitucional, Universidad de Sevilla. Correo electrónico: luisflei@hotmail.com. 


\section{OBJETO.}

El Artículo 150 de la Constitución, ubicado en la Sección IX denominada "Del Poder Ejecutivo", crea el cargo de Vicepresidente de la República. Coherentemente con su denominación, el inciso $1^{\circ}$ de la norma asigna a este cargo la atribución de desempeñar la Presidencia de la República, con las mismas facultades, en caso de vacancia temporal o definitiva.

Por otro lado, el inciso $2^{\circ}$ del propio Artículo 150 indica que el Vicepresidente de la República desempeñará la Presidencia de la Asamblea General y de la Cámara de Senadores, ambos órganos del Poder Legislativo, aspecto que es reiterado por el Artículo 94 inciso $2^{\circ}$ de la Carta, con el agregado de que le otorga expresamente el derecho a voz y voto.

Esto revela una disyuntiva respecto de cuál es la naturaleza del cargo del Vicepresidente de la República. Más aún, descartada su pertenencia al Poder Ejecutivo, dado el diseño constitucional de este sistema orgánico, existe la idea de considerar al Vicepresidente como legislador, como titular de un cargo de legislador, más precisamente de Senador, siguiendo casi exclusivamente la tesis planteada por Justino Jiménez de Aréchaga.

No es posible soslayar que, salvo la del gran Justino, no es detectable una posición clara y precisa de nuestra doctrina constitucional al respecto. Aunque, realizando una lectura detenida y profunda, es posible identificar algunas pistas dejadas con sordina por varios autores patrios. El abordaje de este asunto es pues, el objeto de este trabajo.

\section{UN PUNTO DE PARTIDA: LAS NOCIONES DE LEGISLADOR QUE ADMITE LA CONSTITUCIÓN DE LA REPÚBLICA.}

La cuestión es un problema de la naturalezay composición del cargo de Vicepresidente de la República, en relación con el de Senador, pero además es de interpretación y de aplicación de la Constitución.

Como toda cuestión de interpretación, tiene un punto de partida necesario que es el propio texto constitucional (Gamarra, 2018, pp. 197, 198), lo cual requiere un análisis literal o gramatical que servirá de base para desarrollar luego métodos de interpretación más complejos. 
Cuando los textos de las normas constitucionales refieren a los Senadores, Representantes o al Vicepresidente de la República, no hay confusión respecto del cargo que es objeto de regulación, sin perjuicio de algunas precisiones que se harán en el Capítulo IV.

El problema surge cuando la Constitución utiliza los términos o expresiones genéricas como "legislador", "legisladores", "miembros" o "componentes" de las Cámaras y la Asamblea General, como en los Artículos 77 inciso $2^{\circ}$ numeral 10, 93116 , 117 inciso 3, 118, 147 inciso 3, 148 incisos 4 y 8, 201 y 331 literal c), pues el sentido con el que la Constitución los utiliza no es siempre el mismo.

En algunos casos, estos términos o expresiones son utilizados de modo comprensivo, únicamente, de los titulares de los cargos de Senadores y Representantes, quedando excluido el Vicepresidente de la República.

Es el caso, por ejemplo, del Artículo 117 inciso 3 que regula la retribución de los “legisladores", sin incluir la retribución del Vicepresidente de la República que es regulada por el Artículo 154. O en sede de juicio político, cuando el Artículo 93 de la Constitución identifica el elenco de sujetos comprendidos utiliza la expresión "miembros de ambas Cámaras” en referencia a Senadores y Representantes y a su vez menciona al Vicepresidente, como un cargo diferente.

A nivel infra-constitucional ocurre algo similar, con el Artículo 32 de la Ley 15.851 en sus sucesivas redacciones, en materia de pases en comisión y con el Artículo 10 de la Ley 17.060 respecto del deber de ciertos funcionarios públicos de presentar declaraciones juradas. En ambas Leyes se identifica, por un lado, al Vicepresidente de la República, por el otro, a los "legisladores nacionales".

En otros casos, estos términos o expresiones son utilizados en un sentido funcional, referido a aquellas personas titulares de cargos con el atributo de votar, generar quorum y conformar la voluntad de los órganos que integran el Poder Legislativo, en particular en la Asamblea General. Así ocurre en los Artículos 147 inciso $3^{\circ}$ y 148 inciso $4^{\circ}$, en el procedimiento de censura y en el Artículo 331 literal c) inciso $3^{\circ}$, en el procedimiento de reforma constitucional de la Convención Nacional Constituyente.

Utilizados en este otro sentido, incluyen a los Senadores y Representantes, en quienes el atributo del voto es propio de su condición, y también al Vicepresidente de 
la República, a quien se le atribuye expresamente el voto por el Artículo 94 inciso $2^{\circ}$, diferencia que, según veremos, no es anecdótica.

Lo expuesto, que podría aparentar una contradicción, no lo es, sino que evidencia que estos términos o expresiones adquieren uno u otro significado según el contexto normativo en el que se inserta y eso es válido en la ciencia jurídica, en el marco del método de interpretación sistemática de las normas.

En este sentido, Guastini (2010, p. 72) explica que se hace interpretación sistemática no solo cuando se supone que un término se utiliza siempre con el mismo significado, sino también, cuando se supone que cada término adquiere un significado diferente en función del contexto en el cual se inserta. Cuando una norma constitucional admite dos interpretaciones y una de esas interpretaciones contradice otra disposición constitucional previamente interpretada, en tanto no se produzca una antinomia, se puede hacer interpretación sistemática y escoger la segunda interpretación, descartando la primera.

Siguiendo a Jiménez de Aréchaga (2001a, pp. 136-140) y Cassinelli (2010 pp. 285286), la Constitución de la República admite como métodos de interpretación el textual, el lógico sistemático contextual y el teleológico, sin perjuicio de las sub-perspectivas que a su vez admiten cada uno de estos métodos.

Es entonces dogmática y normativamente admisible que en nuestra Constitución pueden coexistir dos significados de la noción de legislador, con un sentido específico según el contexto normativo en el que se insertan.

Un primer significado refiere al sentido completo o perfecto de legislador, en tanto refiere a la posición jurídica de los titulares de los cargos de Senadores y Representantes, identificados por el mismo régimen en cuanto a su sistema de elección, asunción y cese, su ubicación en el Estado, las atribuciones y su estatuto. Los Senadores y Representantes son legisladores en sentido completo y perfecto, en su dimensión formal, orgánica y funcional.

Por otro lado, la noción de legislador admite un significado en sentido imperfecto o incompleto, referido a quienes constitucionalmente no tienen la misma posición y régimen jurídico que los Senadores y Representantes en los aspectos indicados, sin perjuicio de algunas coincidencias, pero a los cuales la Constitución expresamente les atribuye la potestad de realizar actos propios de la función legislativa. 
Ese segundo significado implica que el legislador en sentido imperfecto o incompleto ejerce también función legislativa, entendida ésta, de acuerdo a Aguirre (1997), como el conjunto de actos "que se ejerce por los órganos competentes para formular y aprobar las leyes, de acuerdo con la Constitución y por los procedimientos que ésta establece” (pp. 25, 28).

Entonces, en el ejercicio de la función legislativa no intervienen solo los Senadores y Representantes, legisladores en sentido perfecto, sino que también lo hace el titular del cargo de Vicepresidente de la República como veremos en el Capítulo III, e incluso el Poder Ejecutivo como surge de los Artículos 85 numeral 6, 86, 133, 168 numerales 7 y 19 de la Constitución, en los que se establece la iniciativa legislativa del Ejecutivo, de los Artículos 134 a 145 y 168 numeral 6, en materia de oposición a la promulgación de las Leyes sancionadas, acto exclusivo del Ejecutivo, del Artículo 168 numerales $4^{\circ}$, respecto de la publicación y circulación de las Leyes y $8^{\circ}$, con la convocatoria a la Asamblea General.

Ahora, esto no transforma en legislador en sentido completo o perfecto, asimilable a Senadores y Representantes, al Vicepresidente de la República, así como tampoco a los titulares de los cargos que soportan al Poder Ejecutivo, sin perjuicio que el caso del Vicepresidente es más complejo para el análisis. Puede considerarse que estamos ante legisladores en sentido funcional, incompleto o imperfecto, pero sin equipararlos a los Senadores y Representantes.

En definitiva, cuando nos referimos al titular de un cargo de legislador, sea de Senador o Representante, aludimos al sentido perfecto o completo de la noción. Cuando nos referimos a quién sin calificar en la posición jurídica de Senador o Representante, con todo lo que ello implica, cumple algún acto de la función legislativa, aludimos al legislador en sentido funcional, imperfecto o incompleto, pero no estamos ante el titular de un cargo de legislador.

\section{EL VICEPRESIDENTE DE LA REPUBLICA ELECTO NO ES TITULAR DE UN CARGO DE LEGISLADOR - SENADOR.}

En nuestra Constitución, son titulares de cargos de legislador los Senadores y los Representantes de acuerdo a lo señalado precedentemente. También, de acuerdo a nuestra Constitución, el cargo de Vicepresidente de la República presenta notorias diferencias jurídicas y políticas con el de Senador, que es con el que se lo tiende a identificar para calificarlo erróneamente como un cargo de legislador. Transitemos por esas diferencias. 


\section{(1) Creación, denominación, ubicación del cargo Vicepresidente de la República:} el leguaje constitucional. La Constitución de 1934 creó, por primera vez, un cargo de Vicepresidente de la República, lo cual fue reiterado en la reforma constitucional de 1938, en la Constitución de 1942 y en la vigente Constitución de 1967, en su Artículo 150: "Habrá un Vicepresidente".

Ello, a diferencia de las Constituciones de 1830 y 1918, en las que si bien existía un Presidente de la República, no existía un cargo de Vicepresidente.

En la Constitución de 1830, era el Presidente del Senado quien cumplía, además de la función de presidir la Cámara, la de suplir al Presidente.

En la Constitución de 1918, en caso de ausencia o enfermedad, el Presidente de la República era suplido por un miembro del Consejo Nacional de Administración, órgano que integraba el Poder Ejecutivo de la época y, en caso de vacancia definitiva, la Asamblea General era convocada para elegir la persona que debía sustituirlo hasta el $1^{\circ}$ de marzo siguiente a las próximas elecciones del Consejo, en cuyo acto debía elegirse el nuevo Presidente.

Adicionalmente, si bien en el caso de las Constituciones de 1934 y 1942, al igual que en la actual de 1967, el Vicepresidente de la República preside además la Cámara de Senadores y la Asamblea General, en la reforma constitucional de 1938 el Vicepresidente no integraba ni presidía ninguno de dichos órganos legislativos e incluso, el ejercicio de su cargo era compatible con el desempeño de otra función pública.

Esto arroja dos datos a considerar:

Primero, que en la Constituciones en las que existió el cargo de Vicepresidente no siempre integró ni se le asignó la Presidencia de la Cámara de Senadores y de la Asamblea General, ni la facultad de voto. A su vez, en las Constituciones en las que no fue previsto el Vicepresidente, la función de suplir al Presidente no siempre fue ejercida por un Senador. Por lo cual, históricamente, no existe una identificación natural y pacífica entre Vicepresidente y Senador.

Segundo, que si el constituyente de 1966 hubiese querido que fuera un Senador el suplente inmediato del Presidente de la República y quien presidiera a su vez la Cámara respectiva y la Asamblea General, así lo hubiese dispuesto, como hizo el constituyente de 
1830. Sin embargo, creó un cargo distinto y específico para ello, que es el de Vicepresidente de la República, opción que no fue ni es inocua.

En todas las Constituciones en que existió un Vicepresidente de la República, el Artículo que creó el cargo estuvo ubicado en la Sección “Del Poder Ejecutivo”, que en la Constitución vigente de 1967 es la IX.

Ello no significa que el Vicepresidente de la República integre el Poder Ejecutivo, pues el diseño que la Constitución diagrama respecto de este sistema orgánico, en los Artículos 149 y siguientes, así lo descarta. Ahora bien, esta ubicación en la Sección que la Constitución reserva para el Poder Ejecutivo, ligada a la propia denominación del cargo Vicepresidente, tiene relevancia semántica.

El prefijo Vice es un elemento compositivo que significa "en vez de" o "que hace las veces de". Por lo que se trata de un prefijo que significa que el nombre completo al que afecta designa a una persona que tiene la autoridad de la designada por la segunda parte del compuesto. El ejemplo clásico de su uso es el de Vicepresidente.

Por lo cual, Vicepresidente es aquel que hace las veces del Presidente cuando éste no está, lo que, sin negar sus otras funciones, pone énfasis en una de las funciones que el Artículo 150 de la Constitcuón le asigna, con una innegable sensación de preponderancia: la de desempeñar, con las mismas facultades y atribuciones, la Presidencia de la República, ante la vacancia temporal o definitiva del Presidente.

El vínculo entre lenguaje y ser, o con lo que algo es, no es un dato desdeñable. El lenguaje es la primera orientación para vislumbrar lo que algo es. Ya Aristóteles (2017) se planteaba que el lenguaje es, en tanto lenguaje de las cosas y el examen de los modos de decir debe relacionarse lo más directamente posible con los modos de ser. La racionalidad del lenguaje está en expresar lo que las cosas son, en tanto presentan la característica de ser decibles.

Con la denominación del cargo Vicepresidente, el lenguaje aporta un primer acercamiento a su realidad y nos orienta a identificar a aquel que suple al Presidente de la República, que hace sus veces cuando no está. No identifica a un legislador.

(2) Elección y sucesión: el quiebre de la regla de la representación proporcional. Existen sustanciales diferencias en el sistema de elección, y en el régimen de suplencias 
y de sustitución, de los Senadores y del Vicepresidente de la República, con innegable trascendencia jurídica y política en el sistema.

El Vicepresidente de la República es una cuña en la representación proporcional de los partidos políticos en la Cámara de Senadores, y por lo tanto en la Asamblea General, orientada a favorecer en el Parlamento las posiciones del Gobierno encabezado por el Presidente. Veamos la razón.

La Constitución, en sus Artículos 77 numeral 9, 79, 88, 94 inciso $1^{\circ}, 95$ y 96, es precisa al establecer que Senadores y Representantes son electos por el Cuerpo Electoral necesaria y exclusivamente en la elección nacional que se celebra en el último Domingo de octubre, cada cinco años.

El sistema para su elección es el de representación proporcional, con matices entre ambos, y ello tiene una trascendencia jurídica y política relevante.

La representación proporcional es un sistema que, desde Thomas Hare y John Stuart Mill, procura la trasferencia o la transformación de los votos de los electores en escaños parlamentarios con algún grado de proporción. La representación proporcional implica, como señala Sartori (1994, pp. 16, 20), un resultado proporcional, la conformación de un órgano representativo que, de alguna manera, más o menos perfecta, refleja la proporción en que se distribuyeron los votos entre los partidos políticos participantes de la elección.

La representación proporcional permite que el Parlamento esté integrado, además de por legisladores del partido del Presidente que resultare electo, por legisladores de los partidos minoritarios, pues es un sistema que no premia a quien obtuvo la mayoría, sino que busca la representación proporcional de todos los partidos, de acuerdo a la cantidad de votos obtenidos.

El sentido político de la representación proporcional es permitir que el Poder Legislativo pueda constituirse en un freno frente a posibles abusos del Poder Ejecutivo, puesto que es este el modo de evitar que el Parlamento sea un mero reflejo de la tendencia política del Poder Ejecutivo, característico en los sistemas electorales mayoritarios (Cassinelli, 2009, pp. 215 - 216).

Por lo que, en principio, podría decirse que la Cámara de Senadores se compone de Senadores que representan proporcionalmente la cantidad de votos obtenidos por cada 
partido político en la referidas elecciones, con el fin de constituirse en un freno al Poder Ejecutivo entendido como Gobierno.

En cambio, por disposición del Artículo 151 de la Constitución, el Vicepresidente de la Republica resulta electo de un modo radicalmente diferente.

Los candidatos a Presidente y Vicepresidente conforman las formulas únicas que presenta cada partido político para competir en las elecciones nacionales que se celebran el último Domingo de octubre, cada cinco años, concomitantemente con las legislativas, resultando electa la fórmula que alcance la mayoría absoluta de los votos. Si ninguna alcanza dicha mayoría, el último Domingo de noviembre siguiente se celebra una segunda elección, en la cual competirán las dos fórmulas más votadas en la primera, resultando electa la que obtenga más votos.

Lo trascendente es que, a diferencia de los Senadores, el sistema de elección del Presidente y Vicepresidente es por mayorías. El sistema mayoritario no procura reflejar la distribución de las votaciones, como sí ocurre en el sistema de representación proporcional, sino que busca un vencedor indiscutible. Su propósito es elegir un Gobierno y, justamente, el premio a la mayoría es crear o reforzar una mayoría que estará a cargo del Gobierno (Sartori, 1994, pp. 17 - 20).

Así entonces, señala Pérez Pérez (1970, pp. 65, 66), en nuestro país se verifica simultáneamente la aplicación de los dos sistemas, porque conviven dos elecciones nacionales. Por un lado, la del Presidente y Vice y, por el otro, la de los legisladores, con sistemas electorales distintos. En la elección parlamentaria se aplica el sistema de representación proporcional. Contemporáneamente, en la elección del Presidente y Vicepresidente, rige el sistema mayoritario.

Esto no es inocuo, jurídica ni políticamente, pues tiene por consecuencia otorgar una ventaja de uno sobre treinta y uno (1/31) en la Cámara de Senadores y de uno en ciento treinta (1/130) en la Asamblea General, para el partido político del Presidente de la República y del Vicepresidente, lo que, por mínimo que sea, genera un desbalance en la representación proporcional de la Cámara de Senadores y la Asamblea General a favor de las posiciones del Gobierno en el Parlamento. 
Cassinelli (2009, p. 224) intenta atenuar este aspecto al señalar que dicha ventaja no guarda racionalidad respecto del sistema de representación proporcional que impera en la Cámara y no logra constituirse en una traición a la regla.

Ahora bien, si bien es real que no se llega a subvertir la regla de la representación proporcional, no puede negarse que el quiebre sí existe, puesto que la intención del constituyente fue desbalancear la representación proporcional parlamentaria a favor del Gobierno.

Ello guarda una relación de racionalidad con el sentido político del sistema de gobierno diseñado por nuestra Constitución -que es un presidencialismo atenuado con elementos parlamentaristas o semipresidencialismo- cuyo propósito es un Gobierno que gobierne, como reconoce el propio Cassinelli (2010, pp. 238, 239), pues a partir de su sistema electoral busca conformar una mayoría legislativa afín al Gobierno, que será: o propia del partido político del Presidente y su Vice, si ganan las elecciones en primera vuelta por mayoría absoluta; o coaligada con otros partidos, si ganan en segunda vuelta. Claramente la ratio constitucional, es lograr Gobiernos que puedan ejercer la dirección política del Estado.

Esta característica es incluso compartida por el parlamentarismo racionalizado, al que algunos autores patrios intentan acercar nuestro sistema, tal como alertan Hauriou (1980, p. 608, 609) respecto del sistema de gobierno de la Constitución Francesa de 1958 y Requejo (2004) respecto del previsto por la Constitución Española de 1978. La representación proporcional pura en los órganos legislativos es un desiderátum para su rol de contrapeso al Ejecutivo. Sin embargo, eso no significa que la incrustación del Vicepresidente de la República en la Cámara de Senadores con el sentido político indicado, no guarde racionalidad con el diseño del sistema de gobierno que prevé nuestra Constitución. Por el contrario, guste o no, se alinea con el sentido político del sistema de gobierno.

Al hilo de lo anterior, Vicepresidente y Senadores también difieren en sus regímenes de suplencia y sustitución, pues al igual que sus sistemas de elección, responden a fines diferentes. En el caso de los Senadores, cada partido político, a través de sus sublemas, presenta al elector una lista $\mathrm{u}$ hoja de votación que establece sus candidatos titulares y suplentes respectivos a la Cámara, de acuerdo al numeral $9^{\circ}$ del Artículo 77 inciso $2^{\circ}$ de la Constitución. Es un sistema por el que cada Senador es sustituido por un suplente respectivo que mantiene la representación proporcional, para lo cual la legislación 
electoral admite varios sistemas entre los que el lema o el sublema debe optar ${ }^{2}$, siempre en un régimen de listas cerradas (Sartori, 1994, pp. 22, 23).

En cambio, el régimen de sustitución del Vicepresidente es prestablecido por la Constitución, surge de la aplicación sistematizada de los Artículos 94 inciso 3, 153 y 155, y sigue la lógica del sistema mayoritario por el que es electo. El Artículo 94 inciso $3^{\mathrm{o}}$ dispone que en los casos en los que el Vicepresidente pase a desempeñar definitiva o temporalmente la Presidencia de la República, o de ocurrir una vacancia en su cargo, desempeñará ambas Presidencias, la de la Cámara de Senadores y la de la Asamblea General, "el primer titular de la lista más votada del lema más votado”.Considerado aisladamente ese Artículo, esta calidad podría recaer en un Senador de un lema partidario que no fuese el de la fórmula presidencial, si dicha fórmula resultara electa en la segunda elección nacional, siempre que en la primera elección resultare con más votos un lema diferente al de esa fórmula.

Para corregir esta posibilidad y mantener la coherencia política buscada por el constituyente entre Presidente, Vicepresidente de la República, Presidente de la Cámara de Senadores y la Asamblea General, en la reforma constitucional de 1997 se estableció, en el Artículo 153, que ante la vancancia temporal o definitiva del Presidente o Vicepresidente "deberá desempeñarla el Senador primer titular de la lista más votada del partido político por el cual fueron electos aquéllos”. Idéntica solución se estableció en el Artículo 155 para cuando las causales de vacancia ocurran antes de la toma de posesión de los cargos.

En definitiva entonces, quien sustituye al Vicepresidente de la República, en caso de vacancia en su cargo, es el Senador titular más votado de la lista más votada del partido político por el cual fueron electos Presidente y Vicepresidente, manteniéndose así el quiebre de la representación proporcional, en favor las posiciones del Gobierno en el Parlamento.

(3) Posición jurídica en el Estado: disociación de los cargos. Los atributos dados al Vicepresidente de la República, que implican el ejercicio de funciones de diversa naturaleza, y la función legislativa que ejercen primordialmente los Senadores, coinciden en el acto del voto con voz en la Cámara y la Asamblea General, que es relevante, pero que es solo uno de los varios que comprende el ejercicio de la función legislativa.

${ }^{2}$ Artículos 12 de la Ley 7.812 y 6 de la Ley 17.113: preferencial, ordinal, respectivo, combinado. 
El contraste de atribuciones y funciones, entre el Vicepresidente y los Senadores, estriba en los aspectos analizados previamente y en la posición jurídica de estos cargos en la estructura jurídica del Estado, lo que nos enfrenta a una dificultad conceptual previa a dilucidar: la relación entre órganos y cargos.

El Estado, como persona jurídica que es, expresa su voluntad a través de las personas físicas. El modo en el cual las personas físicas pueden expresar la voluntad jurídica del Estado, es ocupando los cargos creados por normas jurídicas. Por cargo debe entenderse, siguiendo a Cajarville (2008a, pp. 496, 497), la delimitación jurídica del lugar, la ubicación, el sitio o la posición en la que, luego de ocupar el mismo, una persona física se integrará en la esturctura del Estado y podrá expresar su voluntad. Esa delimitación es realizada por la norma jurídica, para atribuir al cargo un conjunto de potestades, deberes y sujeciones, que deberá cumplir y ejercer la persona que lo ocupe como su titular.

Pero la cuestión es más compleja. Las personas jurídicas, y el Estado en particular, actúan a través de los sistemas orgánicos y los órganos que los componen. Los órganos actúan en un determinado ámbito de competencia, que contiene las atribuciones y los poderes para llevar a cabo tales atribuciones y en un determinado ámbito espacial.

La intersección entre cargo y órgano plantea la interrogante de si el cargo que ocupa la persona física para expresar la voluntad del Estado integra o no el órgano, que es el modo en cual el Estado parcela su actuación en determinados ámbitos de competencia. La cuestión está en distinguir entre la composición del órgano y la conformación de la voluntad del órgano.

Los cargos integran naturalmente el Estado, siempre y en todo caso, pero el cargo no es un elemento del órgano, sino que un cargo puede corresponder o no a un órgano, según el diseño que se establezca en las normas que asignan las atribuciones al cargo.

Puede ocurrir que exista un cargo que no componga a priori un órgano, pero que conforme o coopere en conformar la voluntad de dicho órgano, en tanto las normas atributivas dispongan que la expresión de la voluntad del titular de un cargo se imputa jurídicamente, a través de dicho órgano, al Estado. En tal caso, siguiendo la línea de Sayagués Laso (2002, pp. 184 - 202), Cajarville (2008a, pp. 498, 499) y Rotondo (2017, p. 96) se considerará que el cargo integra, en el sentido de que conforma su voluntad, más no compone, un órgano de la persona jurídica que es el Estado. 
Justamente, un caso que explica esta dicotomía entre componer y conformar la voluntad del órgano, es la posición jurídica que ocupan en el Estado los cargos de Vicepresidente de la República y de Senador.

El Artículo 94 de la Constitución dispone, en su inciso 1", que "la Cámara de Senadores se compondrá de treinta miembros, elegidos directamente (...)”.

Significa que el órgano Cámara de Senadores, que es parte del sistema orgánico Poder Legislativo, que forma parte del Estado, Persona jurídica pública mayor, se compone -éste es el término que usa la norma- de treinta cargos de Senadores que son ocupados por las personas físicas electas como tales por el cuerpo electoral. El término "componer" viene del latin componēre y refiere a las partes que forman o constituyen un todo. Así, la disposición constitucional crea los cargos de Senadores como formando parte o constituyendo el órgano Cámara de Senadores, siendo una consecuencia natural que la voluntad de los Senadores se impute jurídicamente al Estado, a través del órgano referido. Esto explica que la Constitución no asigne expresamente a los Senadores la atribución de votar, sino que ello es una consecuencia jurídica natural de su posición en la estructura del Estado, de su carácter de legisladores en sentido perfecto o completo. El inciso $2^{\circ}$ del Artículo 94 usa una fórmula distinta respecto del Vicepresidente, al agregar que la Cámara de Senadores "será integrada, además, con el Vicepresidente de la República, que tendrá voz y voto y ejercerá su Presidencia, y la de la Asamblea General. 'El uso de los términos “integrada” y “además", y la sistematización de este inciso $2^{\circ}$ con el Artículo 150 de la Constitución, conduce a concluir que si bien el Vicepresidente coopera en la formación de la voluntad de los órganos Cámara de Senadores y Asamblea General, junto a los Senadores, no lo hace como una parte constitutiva o compositiva dichos órganos.

Primero, luego de indicar en el inciso $1^{\circ}$ que la Cámara se "compondrá de treinta miembros", que son los Senadores, el inciso $2^{\circ}$ del Artículo 94 dice que la Cámara "será integrada” por el Vicepresidente de la República. Integrar deriva del latín integrāre, y significa completar un todo con las partes que faltaban. Por lo que quien integra -en el caso el Vicepresidente- no compone una parte -como sí los Senadores- del todo -el órgano Cámara de Senadores-, sino que coopera en la conformación de la voluntad del todo -la Cámara-. Es ésa la sutil y relevante diferencia entre el término "componer", usado por la norma respecto de los Senadores y el término "integrar", usado respecto del Vicepresidente de la República. 
Segundo, reforzando la idea de que el Vicepresidente de la República no compone el órgano, sino que es un cargo exógeno que ayuda a conformar su voluntad, la Constitución de 1942 adicionó al "integrará" en el actual inciso $2^{\circ}$ del Artículo 94, un "además". ¿Además de quiénes? De los miembros, de los propios componentes, que son los Senadores.No hay inocuidad alguna en la expresión: la Cámara "será integrada" -en vez de estará compuesta- por el Vicepresidente y menos inocuidad hay en la adición posterior del "además". Es imposible ocultar la distinción que el constituyente planteó respecto de los Senadores y el Vicepresidente, por más que conformen funcionalmente, de forma conjunta, la voluntad de la Cámara de Senadores y la Asamblea General.

Tercero, el cargo de Vicepresidente se crea por una norma distinta al Artículo 94, que es el Artículo 150 de la Constitución, al disponer "Habrá un Vicepresidente". Si bien la norma está ubicada en la Sección IX "Del Poder Ejecutivo", el cargo de Vicepresidente no compone el Poder Ejecutivo como señalamos.Luego de establecer, en el inciso $1^{\circ}$, que la función primera del Vicepresidente es sustituir al Presidente de la República ante su vacancia, el inciso $2^{\circ}$ del Artículo 150 dice: "desempeñará la Presidencia de la Asamblea General y de la Cámara de Senadores". Esto es reiterado en los mismos términos por el Artículo 94 inciso $2^{\circ}$, al decir que "ejercerá su Presidencia -de la Cámara de Senadores-, y la de la Asamblea General". Ello se sistematiza perfectamente con lo dicho anteriormente, pues ninguna de las dos normas expresa que el Vicepresidente será el Presidente de la Cámara y la Asamblea, o que ocupará el cargo de Presidente o que ocupará la Presidencia, sino que disponen que desempeñará las funciones de los órganos de las Presidencias de la Cámara y de la Asamblea.El Vicepresidente no es titular de los cargos de Presidente de estos órganos, sino que ejerce o desempeña las atribuciones asignadas a ambos cargos por las normas, por lo que, nuevamente decimos, no compone, no es parte constitutiva de ambos órganos, sino que conforma o coopera en la conformación de sus voluntades. Por esta razón, siguiendo a Cagnoni (2006, p. 281) y Rotondo (2017, pp. 96, 125), puede racionalmente sostenerse que el Vicepresidente es un cargo sin órgano, que ejerce las atribuciones que se asignan a las Presidencias de la Cámara y de la Asamblea y su vocación es de expectativa respecto de las atribuciones del cargo de Presidente de la República. Tampoco existe el órgano Vicepresidencia de la República.

Eso explica porqué, a diferencia de los Senadores, la Constitución, en el Artículo 94 inciso $2^{\circ}$, le asigna expresamente al Vicepresidente de la República la atribución del voto en la Cámara y la Asamblea. Al no ser parte natural de los órganos, sino que coopera en la conformación de sus voluntades, no es un legislador natural, perfecto o completo, sino que cumple con un acto específico de la función legislativa asignado expresamente por la Constitución, que de otro modo no podría ejercer. A diferencia de lo que ocurre con los 
Senadores, para quienes dicha atribución no emana de una asignación normativa expresa, sino que es inherente a su cargo.

El de Vicepresidente de la República y los de Senadores, son indudablemente cargos creados por normas diferentes, con posiciones jurídicas distintas en el Estado.

(4) Atribuciones y funciones. Senadores y Representantes ejercen, eminentemente, la función legislativa, mientras que el Vicepresidente de la República ejerce funciones de naturaleza diversa y si bien tiene la atribución del voto, propia de la función legislativa, por asignación expresa, tiene inhibida la realización de otros varios actos de dicha función que sí realizan los Senadores y Representantes.

Como se indicó en el punto previo, los Senadores y Representantes ocupan cargos que componen, forman parte, de las Cámaras respectivas, razón por la cual su atribución principal y casi exclusiva ${ }^{3}$ es el ejercicio de casi la totalidad de los actos comprendidos dentro de la función legislativa por definición constitucional, desde la iniciativa, la elaboración y discusión, la sanción e incluso en la promulgación, con el levantamiento de una eventual oposición del Poder Ejecutivo; con las excepciones que la Constitución reserva al Poder Ejecutivo, como la iniciativa privativa de algunos proyectos de Ley, la oposición y la suspensión de la promulgación de una Ley sancionada y la publicación y circulación de las Leyes ${ }^{4}$.

En cambio, el Vicepresidente es un cargo sin órgano, que no forma parte del Poder Legislativo ni del Poder Ejecutivo, pero que por asignación expresa de la Constitución tiene varias atribuciones, que implican el desarrollo de funciones de naturaleza diversa en ambos sistemas orgánicos.

La primera atribución que la Constitución asigna al Vicepresidente, luego de crear su cargo en el Artículo 150, es la natural a su denominación: suplantar o sustituir, temporal o definitivamente, al Presidente de la República ${ }^{5}$. Ello implica el ejercicio de todos los atributos del Presidente de la República, sea actuando en Consejo de Ministros o acuerdo con los Ministros respectivos, conformando la voluntad del órgano jerarca Poder Ejecutivo ${ }^{6}$ o ejerciendo los poderes que la Carta le asigna al Presidente en su calidad de Jefe de Estado ${ }^{7}$.

\footnotetext{
${ }^{3}$ Pueden realizar accesoriamente algún acto de la función administrativa, aquellos que integren la Comisión Administrativa (Ley 16.821).

${ }^{4}$ Artículos 85 numeral 6, 86, 133, 135 a 145, 168 numerales 4, 6, 7 y 19.

${ }^{5}$ Artículos 150, 153, 155 y 157.

${ }^{6}$ Artículo 149.

${ }^{7}$ Artículos 148, 159, 161, 168 númeral 26, 174 incisos 3 y 4 junto al 184, 175 incisos 1 y 2 y 230.
} 
En esta calidad, únicamente ejercerá función legislativa en los casos puntuales en los cuales lo hace el Poder Ejecutivo como tal, a los que ya referimos.

Hacer las veces del Presidente de la República es la razón principal de la creación del cargo de Vicepresidente, por lo explicado previamente. Si bien tiene una vocación que es de expectativa, o en potencia, respecto del cargo de Presidente de la República, esa vocación es la esencia del Vicepresidente, razón por la cual como dice Cagnoni (1995, p. 18) debe existir una comunicación constante y fluida entre Presidente y Vicepresidente y es tan relevante la señalada sincronía política entre ambos.

La segunda atribución del Vicepresidente de la República, según los incisos $2^{\circ}$ de los Artículos 94 y 150, es ejercer las atribuciones de la Presidencia de la Asamblea General y de la Cámara de Senadores, lo que implica la dirección jerárquica de ambos órganos, junto con los Secretarios respectivos ${ }^{8}$. Ésta, nada tiene de función legislativa, sino que es pleno ejercicio de función administrativa.

Según los Reglamentos de la Asamblea General ${ }^{9}$ y de la Cámara de Senadores ${ }^{10}$, dictados al amparo del Artículo 105 de la Constitución, el ejercicio de las Presidencias consiste en dirigir administrativamente las sesiones de la Cámara y la Asamblea, presentar los proyectos de presupuesto de la Cámara que se aprueban por Resolución administrativa ${ }^{11}$, pasando por la desingación, destitución y sanción de los funcionarios de la Cámara, entre otras cuestiones.

También en el ejercicio de esa atribución debe resolver la adjudicación de licitaciones como ordenador de gastos primario de la Cámara y la Asamblea General, atento al Artículo 27 literal c) del TOCAF, así como resolver recursos administrativos contra actos de la Cámara o de la Asamblea o la Comisión Administrativa, atento a los Artículos 317 de la Constitución y $7^{\circ}$ de la Ley 16.821.

Dichas actividades no integran el grupo de actos que conforman el procedimiento establecido en la Constitución para la sanción y la promulgación de las Leyes que define a la función legislativa, sino que como señala Delpiazzo (2006, p. 67), se trata de un conjunto de actos jurídicos y materiales que se realizan en apoyo de la función legislativa, pero que no son tal, sino que implican el ejercicio de función administrativa. Esto pues si bien manifiestan la voluntad de dos órganos legislativos, no pueden definirse como

\footnotetext{
${ }^{8}$ Artículos 105 y 107 de la Constitución.

${ }^{9}$ Artículo 93.

${ }^{10}$ Artículo 122.

${ }^{11}$ Artículo 108 de la Constitución.
} 
función legislativa, ni jurisdiccional ni constituyente, en tanto no integran el tracto procedimental requerido para el dictado de los actos propios de esas funciones, que son las leyes (Cajarville, 2008a, pp. 135-142).

Además de la diferencia obvia, en cuanto a que el Vicepresidente ejerce función administrativa, y no los Senadores, ello marca otra más sutil en cuanto al Principio que nutre sus actuaciones en los órganos legislativos. Mientras que los Senadores siempre, al ejercer su función, actúan con una natural y esperada parcialidad política; el Vicepresidente, al ejercer la Presidencia de la Cámara y la Asamblea, dirigir las sesiones y demás, debe actuar bajo influjo del Principio de imparcialidad inherente a la función administrativa (Cajarville, 2008b, pp. 152,153), el que solo quiebra puntualmente al emitir voz y voto en las sesiones cuando pasa a actuar con parcialidad política.

La tercer atribución constitucional del Vicepresidente de la República es ejercer voz y voto tanto en la Cámara de Senadores como en la Asamblea General, por asignación expresa del Artículo 94 inciso 2. Es el único acto de la función legislativa que ejerce el Vicepresidente con el que quiebra su imparcialidad.

Igualmente, hay dos diferencias sustanciales con los Senadores.

En primer lugar, como se explicó, la Constitución asigna expresamente al Vicepresidente la atribución del voto en la Cámara y la Asamblea. Al no ser parte de dichos órganos, ni un legislador en sentido perfecto o completo, el Vicepresidente ejerce un acto de la función legislativa sólo porque la Constitución se lo asignó expresamente, pues de otro modo no podría hacerlo, en tanto no es un acto inherente a su cargo, a diferencia de lo que ocurre con los Senadores.

En segundo lugar, si bien el Vicepresidente tiene voz y voto en la Cámara y la Asamblea, no ejerce la función legislativa completa, como sí los Senadores. La función legislativa implica además de la voz y la emisión del voto en el Cuerpo respectivo por parte del legislador, una tarea casi tan fundamental como ésta que es la de elaborar -o en su caso perfeccionar la elaboración- los proyectos de Ley que se someterán luego a la voluntad del Cuerpo. Es donde se despliega con mayor plenitud la deliberación parlamentaria.Esta tarea se desarrolla en las Comisiones parlamentarias, cuya previsión surge de los Reglamentos de las Cámaras ${ }^{12}$ y de la Ley 16.698 y se integran con Senadores o Representantes según la Cámara.

\footnotetext{
${ }^{12}$ Artículo 105 de la Constitución.
} 
Ahora bien, por disposición expresa del Artículo 125 del Reglamento de la Cámara de Senadores, el Presidente, es decir, el Vicepresidente de la República, "no podrá integrar ninguna Comisión de la Cámara”, pudiendo tan solo "asistir a todas con voz, pero sin voto”, cosa que de hecho tampoco hace. Es más, el Vicepresidente de la República, al ejercer las Presidencias de la Cámara de Senadores y la Asamblea General, tiene prohibido "discutir ni abrir opinión sobre el asunto en debate mientras esté presidiendo salvo el fundamento del voto”, según los Artículos 123 del Reglamento de la Cámara y 93 numeral 16 del Reglamento de la Asamblea.

Ambos aspectos, pero principalmente el primero, son un limite al ejercicio de función legislativa en comparación con los titulares de cargos de legisladores, los Senadores y Representantes. La razón de dicha cortapisa radica en una priorización normativa del principio de imparcialidad que inficiona la responsabilidad orgánica del Vicepresidente de la República, al ejercer las atribuciones de las Presidencias de la Cámara y la Asamblea, por sobre su parcialidad política.

(5) Diacronía: asunción y cese. El nuevo Vicepresidente de la República electo y los nuevos Senadores asumen sus cargos en momentos diferentes.

Mientras que los Senadores asumen sus cargos el 15 de febrero del año siguiente al de la elección, que es cuando empieza a sesionar la nueva Asamblea General, el Vicepresidente asume junto con el Presidente de la República el $1^{\circ}$ de marzo ${ }^{13}$.

La cuestión más interesante se plantea respecto del cese, en tanto aporta otra razón que abona la tesis de la disociación de ambos cargos.El Artículo 152 de la Constitución dispone que el Presidente y el Vicepresidente "durarán cinco años en sus funciones". Si asumen el $1^{\circ}$ de marzo del año siguiente a la elección, serán titulares de sus cargos durante cinco años, es decir, hasta el $1^{\circ}$ de marzo del quinto año siguiente a su asunción, que es el posterior a la próxima elección nacional, día en el cual cesan.

Ahora bien, de acuerdo al incisos $1^{\circ}$ y $2^{\circ}$ del Artículo 104, ocurre que entre el 15 de febrero, fecha en que asumen los nuevos Senadores y el $1^{\circ}$ de marzo, fecha de cese del anterior Presidente y Vicepresidente de la República y asumen los nuevos, quien ejerce la Presidencia de la Asamblea General y de la Cámara de Senadores es el Senador más votado de la lista más votada.

${ }^{13}$ Artículos 104 y 158 de la Constitución. 
En consecuencia, entre el 15 de febrero y el $1^{\circ}$ de marzo del año siguiente a la elección, el Vicepresidente deja de ejercer las funciones de las Presidencias de la Cámara y la Asamblea e incluso deja de tener voz y voto en ambas, por lo cual ya no ejerce función legislativa. Sin embargo, no cesa en su cargo, continúa con su atribución natural que es su vocación esencial: suplantar y sustituir al Presidente de la República en ese lapso ${ }^{14}$, lo cual demuestra, además de la diacronía, la disociación entre los cargos de Vicepresidente y Senador.

Esta disociación también se expresa en el procedimiento de censura parlamentaria de los Ministros, pues la disolución de las Cámaras por el Presidente de la República, que prevé el Artículo 148 de la Constitución, supone el cese de los Senadores y Representantes, más no del Vicepresidente, quien continúa con su atribución natural de sustituto del Presidente.

(6) Primeras conclusiones. Crítica a la posición de Jiménez de Aréchaga. El único autor patrio que se ha pronunciado expresamente al respecto es Justino Jiménez de Aréchaga, identificando al Vicepresidente como un Senador, lo cual nos coloca en posición de debate con el maestro.

En el Tomo II de la Constitución Nacional (2001b), cuando analizaba la posición del Vicepresidente de la Republica en la Cámara de Senadores, a partir del Artículo 85 de la Constitución de 1942 -hoy Artículo 94-, comentaba de forma crítica que según su parecer "es una formula inconveniente (...) pudiendo provocar la integración del Senado con el Vicepresidente de la República graves dificultades (...)” (p. 171).

Agregaba luego:

(...) en 1942 se planteo un problema acerca de la condición jurídica del Vicepresidente de la República. Se preguntaba: ¿es un Senador? ¿Puede ser Ministro? Alguien sostuvo que no era un Senador, porque el artículo 85 dice que el Senado lo componen 30 miembros y que, además, la integrará el Vicepresidente de la República (...) entiendo que el Vicepresidente de la República es un Senador (...) porque es un integrante del Senado con voz y voto (Jiménez de Aréchaga, 2001b, p. 172).

La conclusión de Justino se sostiene en dos premisas erróneas.La primera, que ya fue objeto de análisis en este Capítulo, es la afirmación de que porque se le ha asignado 
de forma expresa el derecho a voz y voto entonces al Vicepresidente de la República es un Senador. La asimilación de ambos cargos por la coincidencia en la potestad de votar, implica desconocer sus sustanciales diferencias jurídicas y políticas, que van desde su denominación, pasando por su sistema de elección y sustitución, posición que ocupan en el Estado, atribuciones, momento de asunción y cese de los cargos, hasta sus requisitos, inelegibilidades y su retribución, como veremos en el final. Puede decirse que el Vicepresidente de la República es un legislador en un sentido funcional, pero incompleto o imperfecto, e incluso parcial, pues tiene inhibidos varios actos de la función legislativa. No es entonces titular de un cargo de legislador, puesto que no es asimilable a un Senador en el sentido perfecto o completo del cargo.

En segundo lugar, la conclusión de Jiménez de Aréchaga tiene como presupuesto una hipótesis desiderativa que el autor expresa en el Tomo III de su obra, que carecía de anclaje ya en el texto constitucional de 1942, que tampoco lo tiene en el actualmente vigente y que no puede ser una consecuencia extraíble por interpretación de la Constitución. Previo a criticar la figura del Vicepresidente de la Republica, por afectar el principio de la representación proporcional integral del Senado, Jiménez de Aréchaga (2001c, p. 57) expresaba:

Pudo haber dicho muy bien: los Senadores serán 31; (...) y uno de ellos que presidirá el Cuerpo (...) y por otra disposición pudo agregarse que, en caso de vacancia, ausencia, etc., del Presidente de la República, éste será sustituido por el Presidente del Senado (p. 56),

Justino parte de lo que la Constitución "pudo haber dicho" pero no dijo, en el marco de una crítica a la figura del Vicepresidente. Su tesis tiene un componente desiderativo de que la Constitución fuese diferente a la que era y es.

Si el constituyente hubiese coincidido con Justino, y hubiese querido que fuese un Senador el suplente inmediato del Presidente de la República y quien presidiera a su vez la Cámara y la Asamblea General, así lo hubiese consignado en el texto, como en la Constitución de 1830 .

Sin embargo no lo hizo, y deliberadamente creó un cargo específico para ello, cuyo titular es electo por el sistema electoral mayoritario que quiebra, intencionalmente, el principio de la representación proporcional integral de la Cámara de Senadores, como se analizó, para fortalecer así las posiciones del Gobierno en el Parlamento. 
La conclusión de Jiménez de Aréchaga respecto de que el Vicepresidente de la República es un Senador no se ajusta textual ni contextualmente a la Constitución, ni tampoco al sentido político del sistema de gobierno que, agrade o no, es el que nos presenta la norma fundamental.

\section{CONCLUSIÓN. LA CUESTION DE SU ESTATUTO.}

La conclusión parece obvia. El Vicepresidente de la República es un cargo creado por el Artículo 150 de la Constitución, distinto y disociable del de Senador, con una posición y régimen jurídico y un sentido político, específicos. Entonces, dado que en la Constitución los cargos de legislador corresponden a Senadores y Representantes, el de Vicepresidente de la República, por sus múltiples diferencias con el de Senador, no puede ser identificado como tal.

Lo anterior no implica negar que el Vicepresidente de la República ejerce, aunque parcialmente, función legislativa, al tener atribuida expresamente la potestad de voz y voto en la Cámara de Senadores y la Asamblea General.

Puede decirse entonces que el Vicepresidente de la República no es titular de un cargo de legislador, más sí es legislador en el sentido funcional, imperfecto o incompleto, conclusión que responde a una interpretación textual y lógico sistemática, que respeta, siguiendo a Konrad Hesse (2012, pp. 68, 69), la unidad funcional y política de la Constitución. La distinción no es baladí, sino que es relevante al momento de interpretar y concretar las normas constitucionales que incluyen términos como "legislador", "legisladores", “miembros" o "componentes" de la Cámara de Senadores y de la Asamblea General, mencionadas en el Capítulo II, y así determinar si el Vicepresidente está comprendido como sujeto de su regulación.

Si la disposición constitucional utiliza el término o expresión en referencia a la noción de legislador en sentido perfecto o completo, acotada solo a los cargos de legislador, Senadores y Representantes; o si lo hace en sentido funcional, imperfecto e incompleto, incluyendo, además de los Senadores y Representantes, al Vicepresidente de la República. 
En cuanto al estatuto del Vicepresidente de la República, la Constitución dispone requisitos positivos y negativos para su elección e inelegibilidades ${ }^{15}$, así como un régimen de retribución ${ }^{16}$, propios del cargo de Vicepresidente y distintos al cargo de Senador ${ }^{17}$. Lo urticante, que merece ser analizado, se plantea respecto de los fueros, incompatibilidades y prohibiciones.

La Constitución de la República prevé en los Artículos 112 a 114 los fueros parlamentarios, que conforman un plexo integrado por la irresponsabilidad por los votos y opiniones, la inmunidad de arresto e inmunidad de procesamiento por cualquier delito. Las tres normas solamente refieren, literalmente, a los Senadores y Representantes. A su vez, los fueros son extendidos al Presidente y a los Ministros, por los Artículos 171 y 178.

El único cargo sin mención textual es el de Vicepresidente de la República, lo que no significa que no quede amparado por los fueros, ni que deba forzarse la inclusión del Vicepresidente en el cargo de Senador para ampararlo.

Primero, cuando el Vicepresidente de la República sustituye al Presidente por vacancia, éstos pasan a serle aplicables por disposición del Artículo 171, que extiende las inmunidades al Presidente. Si bien la norma menciona sólo las inmunidades, se acepta que la misma utiliza el término en sentido amplio, reenviando al plexo de fueros parlamentarios de los Artículos 112 a $114^{18}$.

Segundo, cuando el Vicepresidente actúa en ejercicio de las Presidencias de la Cámara de Senadores y de la Asamblea General, incluida la atribución de voz y voto, la solución emana de una interpretación teleológica y de la aplicación del Artículo 72 de la Constitución.

El origen del sentido contemporáneo de los fueros se ubica en Inglaterra, en la construcción de lo que es hoy el Principio de separación de poderes y en el génesis de la forma republicana de gobierno de la Francia revolucionaria. Su fin no es proteger a título personal a los Senadores y Representantes, sino a la independencia político institucional del Poder Legislativo en sí, como entienden pacíficamente Jiménez de Aréchaga (1983, pp. 58, 59), Cassinelli (2009, p. 232), Korzeniak (2006, p. 516) y Correa Freitas (2009, p. 49).

\footnotetext{
${ }^{15}$ Artículos 151 inciso final y 152.

${ }^{16}$ Artículos 154.

${ }^{17}$ Artículos 98, 100, 117 inciso $3^{\circ}$.

${ }_{18}$ Solo Cassinelli (2009, p. 241) plantea alguna duda al respecto, aunque parece volcarse por la interpretación amplia referida.
} 
Si la finalidad de los fueros es asegurar que la conformación de la voluntad de los órganos del Poder Legislativo sea independiente y libre de toda presión o injerencia, en especial a través del Poder Judicial, lo ajustado a dicho fin es entender que el Vicepresidente está amparado por los fueros, pues, a pesar de no haber sido mencionado por las normas, su voluntad coopera en la conformación de la voluntad legislativa de la Cámara de Senadores y de la Asamblea General, ambos órganos del Poder Legislativo.

Nuestra Constitución aporta una herramienta para el anclaje normativo de lo señalado. Dado su fin, los fueros son una garantía del Principio de separación de poderes, pilar fundamental de la forma republicana de gobierno que consagra el Artículo 82 y del Estado de Derecho. Como consecuencia, los fueros son una garantía inherente a la forma republicana de gobierno, lo cual remite a la fórmula del Artículo 72: "la enumeración de los derechos, deberes y garantías hecha por la Constitución, no excluye los otros (...) inherentes a la forma republicana de gobierno".

La falta de enunciación textual de esta garantía para el Vicepresidente, no es razón eficiente para considerarlo excluido de los fueros, en la medida que se trata de una garantía inherente a la forma republicana de gobierno, que va más allá de la literalidad de los Artículos 112 a 114 y trasciende a Senadores y Representantes, pues protege al Poder Legislativo en sí, y a todos quienes cooperan en la conformación de la voluntad legislativa de sus órganos.

Algo similar sucede con las incompatibilidades y las prohibiciones previstas por los Artículos 122 a 126, pues refieren literalmente a los Senadores y Representantes, salvo el Artículo 123 que refiere a la función legislativa. El Artículo 171 las hace aplicables al Presidente de la República y el Artículo 178 a los Ministros. Por lo cual huelga, únicamente, la mención textual del Vicepresidente.

No caben dudas que cuando el Vicepresidente sustituye al Presidente por vacancia, se le aplican estas inhibiciones por disposición del Artículo 171. El problema surge cuando el Vicepresidente no actúa en su atribución natural, sino conformando la voluntad del Poder Legislativo, pues no hay una norma que en principio ancle textualmente el cargo a tales inhibiciones.

La cuestión presenta un grado mayor de dificultad, pues desde la deóntica jurídica se entiende, en términos generales, que las normas que prevén prohibiciones e incompatibilidades son de aplicación e interpretación restringida, puesto que limitan la libertad de las personas. 
La primera opción sería considerarlas inaplicables al Vicepresidente salvo cuando sustituye al Presidente, atendiendo a una interpretación restricta y literal. Sin embargo, es posible plantear una segunda opción.

Primero, en este caso sucede un fenómeno de ausencia de una regla justa o correcta, pues las normas prevén incompatibilidades y prohibiciones comunes para los Senadores,

Representantes, Presidente de la República, Ministros, más no para el Vicepresidente, sin que exista una razón para esta falta.

Segundo, estas prohibiciones e incompatibilidades no apuntan a limitar la autonomía de la voluntad de las personas que eventualmente ocupan los cargos en cuestión, sino que, siguiendo el razonamiento de Jiménez de Aréchaga (1983, pp. 51-53), tienen por objeto impedir que quienes expresan la voluntad del Poder Legislativo o del Poder Ejecutivo actúen simultáneamente en o para o en relación con otros Poderes del Estado, evitando influencias, incidencias y trasiegos indebidos de intereses. No estamos en un supuesto en el cual una norma ingresa y limita el ámbito privado de autonomía de la voluntad de las personas, sino que su fin es asegurar la independencia de acción del Poder Legislativo, y también del Poder Ejecutivo, por lo que estas prohibiciones e incompatibilidades son un principio fundamental de organización de los Poderes (Jiménez de Aréchaga, 1983, p. $53)$.

Tercero, sobre esabase, puede entenderse queestas prohibiciones eincompatibilidades no son más que fórmulas que encierran un cúmulo de deberes de no hacer, para todos quienes tienen la atribución de expresar la voluntad de los Poderes del Estado, incluido el Vicepresidente, que son inherentes a la forma republicana de gobierno pues garantizan el Principio de separación de poderes.

Lo señalado nos devuelve al Artículo 72 de la Constitución, que positiviza todas las garantías y deberes inherentes a la forma republicana de gobierno, aún aquellos que no estén enumerados expresamente en ella. Dada la sistematicidad natural del Artículo 72 con el 332 de la Constitución, los deberes inherentes a la forma republica de gobierno alcanzan también a las "autoridades públicas". Así, el Vicepresidente de la República debe entenderse alcanzado por los mismos deberes de no hacer, ínsitos en tales incompatibilidades y prohibiciones. 


\section{BIBLIOGRAFIA CONSULTADA.}

AGUIRRE, G. (1997). Derecho Legislativo - Teoría General de la Ley Tomo I. Montevideo. FCU.

ARISTÓTELES, GIANNINI, H., FLISFISCH, M. (2017). Las Categorías. Introducción, traducción, notas e Index Graecus Translations. Santiago de Chile. Editorial Universitaria.

CAGNONI, J. (1995). “El Vicepresidente de la República”, Revista de Derecho Público, No 8, p. 9.

CAGNONI, J. (2006). El Derecho Constitucional Uruguayo, Montevideo, FCU.

CAJARVILlE, J. (2008a). Sobre Derecho Administrativo Tomo I. Montevideo. FCU.

CAJARVILLE, J. (2008b). Sobre Derecho Administrativo Tomo II. Montevideo. FCU.

CASSINELli, H. (2009). Derecho Público. Montevideo. FCU.

CASSINELli, H. (2010). Derecho Constitucional y Administrativo. La Ley - Uruguay.

COMMONS, J. (1907). Proportional Representation. New York. The MacMillan Company.

CORREA FREITAS, R. (2009). Derecho Constitucional Contemporáneo, Tomo II. Montevideo. FCU.

DELPIAZZO, C. (2006). Derecho Administrativo Especial Vol. 1. Montevideo. Amalio Fernández.

GAMARRA, D. (2018). La interpretación de la Constitución y la ley. La Ley - Uruguay.

GUASTINI, R. (2010). Teoría e ideología de la interpretación constitucional, Instituto de Investigaciones jurídicas. Madrid. Editorial Trotta.

HAURIOU, A., GIQUEL, J., GÉLARD, P. (1980). Derecho Constitucional e Instituciones políticas. Barcelona. Seix Barral.

HESSE, K. (2012). Escritos de Derecho Constitucional. Madrid. Centro Estudios Polítcos y Constitucionales.

JIMÉNEZ DE ARÉCHAGA, J. (1983). Teoría de Gobierno Tomo II. Montevideo. FCU.

JIMÉNEZ DE ARÉCHAGA, J. (2001a). La Constitución Nacional Tomo I. Montevideo. Cámara de Senadores.

JIMÉNEZ DE ARÉCHAGA, J. (2001b). La Constitución Nacional Tomo II. Montevideo. Cámara de Senadores.

JIMÉNEZ DE ARÉCHAGA, J. (2001c). La Constitución Nacional Tomo III. Montevideo. Cámara de Senadores.

KORZENIAK, J. (2006) Primer Curso Derecho Público. Derecho Constitucional. Montevideo. FCU.

PÉREZ PÉREZ, A. (1970). La Ley de Lemas. Montevideo. FCU.

REAL ACADEMIA ESPAÑOLA (2018). Diccionario de la Lengua Española.

REQUEJO, J. (2004). “Las relaciones entre el Gobierno y las Cortes Generales”, Revista Española de Derecho Constitucional, , No 70, p. 73 - 89. 
ROTONDO, F. (2017). Manual de Derecho Administrativo. Montevideo.

SARTORI, G. (1994). Ingeniería Constitucional Comparada. Una investigación de estructuras, incetivos y resultados. México. Fondo de Cultura Económica.

SAYAGUÉS LASO, E. (2002). Tratado de Derecho Administrativo Tomo I. Montevideo. FCU.

Fecha de recepción: 10 diciembre 2020 Fecha de aceptación: 6 de marzo 2021 